\title{
Clinico-Diagnostic Experience with Cervical Lymphadenopathy Patients in a Tertiary Health Care Hospital

\author{
Dr. Kashmir Singh ${ }^{1}$, Nirmal Chand Kajal ${ }^{2}$, Ritu Dadra ${ }^{3 *}$, Jasvir Kaur ${ }^{4}$, P. Prasanth ${ }^{3}$
}

${ }^{1}$ Medical Officer, MD Medicine, ESI Hospital, Amritsar, Punjab-143001, India

${ }^{2}$ Professor, Department of Chest and TB, Govt Medical College, Amritsar, Circular Road, Amritsar, Punjab-143001, India

${ }^{3}$ Junior Resident, Department of Chest and TB, Govt Medical College, Amritsar, Circular Road, Amritsar, Punjab-143001, India

${ }^{4}$ Senior Resisdent, Department of Chest and TB, Govt Medical College, Amritsar, Circular Road, Amritsar, Punjab-143001, India

DOI: $10.36347 /$ sjams.2020.v08i05.002

| Received: 23.04.2020 | Accepted: 30.04.2020 | Published: 06.05.2020

*Corresponding author: Dr. Ritu Dadra

\section{Abstract}

Original Research Article

This is an observational prospective study, which include 60 patients with cervical lymphadenopathy which came to outpatient department or got admitted in the wards. Clinico-diagnostic profile of these cases was determined. Among 60 cases of cervical lymphadenopathy, females $(34,56.6 \%)$ were more than the male $(26,43.3 \%)$ patients and most of the patients were at the age group of 21-30 years. Most patients presented with fever $(66.1 \%)$, weight loss $(50 \%)$, night sweating $(40 \%)$, anorexia (46.66\%), and cough (30\%). $54(86.66 \%)$ cases were diagnosed by fine needle aspiration cytology (FNAC) and 6 (13.3\%) were diagnosed by biopsy. 44 (73.33\%) had caseous necrosis, 54 (90\%) had epithelioid cells, and $16(26.67 \%)$ had giant cells. Previous history of anti- tubercular therapy (ATT) was present in 20 (33.3\%) patients, 16 (26.6) of them took ATT for lymph node TB and 4 (6.66) patients took ATT for pulmonary tuberculosis (TB). 8 (13\%) patients has other diagnosis than TB, 4 of them has Hodgkins lymphoma, 2 has other malignancy (carcinoma breast) and 2 has reactive lymphadenitis. Cervical lymphadenopathy can have varied manifestation from non-neoplastic to neoplastic condition. Proper history, examination and relevant investigations and disease specific treatment can only cure the patient and improve the prognosis. Fine-needle aspiration is a safe, easy, accurate, and valuable tool for the evaluation of cervical adenopathy.

Keywords: Fine needle aspiration cytology, Anti-tubercular therapy; epithelioid cells; lymph nodes, caseous necrosis. Copyright @ 2020: This is an open-access article distributed under the terms of the Creative Commons Attribution license which permits unrestricted use, distribution, and reproduction in any medium for non-commercial use (NonCommercial, or CC-BY-NC) provided the original author and source are credited.

\section{INTRODUCTION}

The term lymphadenopathy is used to describe the conditions in which lymph nodes become abnormal in size, shape, consistency or number [1]. Lymph nodes are strategically placed along the drainage of tissue and body fluids. Humans have approximately 600 lymph nodes throughout the body [2]. Lymphadenopathy is usually benign and self-limiting in most patients. The etiology varies from simple inflammation to malignancies and tuberculosis, sometimes it may be non-specific. A high index of suspicion is required to reach to a diagnosis.

$\mathrm{TB}$, which mainly involves the lungs can also cause infection in almost all other organs and tissues in the body. Tubercular lymphadenitis is the most common form of extrapulmonary manifestations of TB in developing countries like India. Fine needle aspiration cytology has been important tool to make the diagnosis in cervical lymphadenopathy. Role of FNAC as the first line investigational technique for the diagnosis of cervival lymphadenopathy has previously been studied [3, 4].

Tuberculous lymphadenitis needs to be differentiated from lymphadenopathy due to other causes. These include conditions such as HIV, Mycobacteria other than tuberculosis (MOTT), fungi, toxoplasmosis, autoimmune conditions, drug hypersensitivity, reactive hyperplasia, lymphoma, leukemias, metastases, Kaposi sarcoma, sarcoidosis and other miscellaneous conditions. In tuberculous lymphadenitis features such as multiplicity, matting and caseation are usually present but these are neither specific nor sensitive. In lymphoma, the nodes are usually rubbery in consistency and are seldomly matted. In lymphadenopathy due to carcinoma, the nodes are usually hard and fixed to the underlying structures or the overlying skin.

Directly observed treatment short course (DOTS) for TB is effective in treating tuberculous lymphadenopathy which includes 6 month regimen 
containing isoniazid, rifampicin and pyrazinamide, ethambutol for 2 months followed by isoniazid, riframpicin and ethambutol for 4 months given on daily basis.

\section{Materials ANd Methods}

It was a prospective observational study done among 60 patients with cervical lymphadenopathy attending the outpatient and inpatient department of chest and TB hospital over a period of 6 months. All cases were studied after taking written informed consent. Data was collected regarding age, sex, duration of symptoms, constitutional symptoms and history of contact with tuberculosis patient.

A detailed local and complete general physical examination was carried out followed by work up investigations including FNAC or lymph node biopsy. TB diagnosis was based on the findings of granulomatous inflammation in the specimen. Having come to conclusion of diagnosis, treatment was instituted appropriately. Medical treatment was employed predominantly for conditions like tubercular adenitis, infective lymph node swellings. In the present study, all cases proved as tubercular were started ATT as per national tuberculosis elimination programme.

\section{RESUlTS AND DICUSSION}

Cervical lymphadenopathy is a commonly observed entity by clinicians throughout the world. In the present study the cervical lymphadenopathy was most commonly due to tuberculosis. Extrapulmonary TB affects LNs, gastrointestinal tract, musculoskeletal system, genitourinary system, central nervous system (CNS), pleura, and pericardium, although any organ can be involved. Kent et al., found that CTL is the result of lympho-hematogenous spread of pulmonary tuberculosis [5] Lymph node tuberculosis could be also occurring by direct exposure to infection [6]. CTL is more frequent in females and in the younger age groups, whereas pulmonary tuberculosis is more common in males and in the older age groups [7-9].

CTL may present as a unilateral single or multiple painless lump, mostly located in the posterior cervical or supraclavicular region $[10,11]$. The duration of lymphadenopathy at time of presentation is typically 1-2 months, varying from 3 weeks to 8 months [12, 13]. Fistula formation can be seen in almost $10 \%$ of the mycobacterial cervical lymphadenitis though it is rare in atypical cases $[10,14,15]$.

A study done by Khandkar et al., [16] found that female- to- male ratio for LNTB was 2.8:1. Our study also showed that LNTB was more common among women. Among 60 cases of cervical lymphadenitis females $(34,56.6 \%)$ were more than the male $(26,43.3 \%)$ patients. Golden and Vikram [6] documented a skewed unimodal distribution toward younger age (25-34 years) in LNTB populations, while displaying a bimodal distribution in their PTB population with peaks at 25-34 years and 65+ years. In our study, most of the patients were in 21 to 30 years age group.

Most patients presented with fever $(66.1 \%)$, weight loss (50\%), night sweating $(40 \%)$, anorexia $(46.66 \%)$, and cough (30\%) (Table-1). 38 (63.33\%) patients presented with multiple enlarged lymph node group and $22(36.6 \%)$ had involvement of a single group. In addition to cervical lymph node involvement axillary group involvement was present in 8 (13.3\%). Matting of the lymph node was present in $42(70 \%)$ cases, $40(66.6 \%)$ had tenderness, and $8(13.3 \%)$ had discharge (Table-2).

$52(86.66 \%)$ cases were diagnosed by FNAC and $8(13.3 \%)$ were diagnosed by biopsy. Among 60 cases, $44(73.33 \%)$ had caseous necrosis, $54(90 \%)$ had epithelioid cells, and $16(26.67 \%)$ had giant cells (Table-3). Regarding other test results, 16 (26.66\%) cases had a positive Mantoux test. 10 (16.6\%) had concomitant pulmonary $\mathrm{TB}$ and $6(10 \%)$ was found sputum positive for acid fast bacilli (AFB).

Previous history of ATT was present in 20 (33.3\%) patients, 16 (26.6) of them took ATT for LNTB and 4 (6.66) patients took ATT for pulmonary tuberculosis. $8(13 \%)$ patients have other diagnosis than TB, 4 of them has Hodgkins lymphoma, 2 has other malignancy (carcinoma breast) and remaining 2 has reactive lymphadenitis (Table-4).

Tuberculous lymphadenitis may respond slowly to standard anti-tubercular treatment, with persistent discomfort. Frequent patient follow- up during treatment is recommended for reassurance and management of local discomfort. 
Table-1: Clinical Characteristics of Patients

\begin{tabular}{|c|c|c|c|}
\hline \multicolumn{2}{|l|}{ Features } & Frequency & Percentage \\
\hline \multirow{2}{*}{ Gender } & Male & 26 & 43.3 \\
\hline & Female & 34 & 56.6 \\
\hline \multirow{5}{*}{ Age Group (Years) } & $<20$ & 20 & 33.3 \\
\hline & $21-30$ & 26 & 43.3 \\
\hline & $31-40$ & 6 & 10 \\
\hline & $41-50$ & 4 & 6.6 \\
\hline & $>50$ & 4 & 6.6 \\
\hline \multirow{3}{*}{ Previous History of ATT } & Present (LN TB) & 16 & 26.6 \\
\hline & Pulmonary TB & 4 & 6.6 \\
\hline & Not Present & 40 & 66.6 \\
\hline \multirow[t]{5}{*}{ Symptoms } & Fever & 40 & 66.6 \\
\hline & Night sweating & 24 & 40 \\
\hline & Anorexia & 28 & 36.6 \\
\hline & Cough & 18 & 30 \\
\hline & Weight loss & 30 & 50 \\
\hline
\end{tabular}

LNTB- Lymph node tuberculosis; ATT- Anti-tubercular therapy

Table-2: Lymph Node Study Findings

\begin{tabular}{|l|l|l|l|}
\hline \multicolumn{2}{|c|}{} & No. of Patients & Percentage \\
\hline \multirow{2}{*}{ Number of group involved } & Single & 22 & 36.7 \\
\cline { 2 - 4 } & Multiple & 38 & 63.3 \\
\hline \multirow{2}{*}{ Matting of LN } & Present & 42 & 70.0 \\
\cline { 2 - 4 } & Absent & 18 & 30.0 \\
\hline \multirow{2}{*}{ Denderness } & Present & 40 & 66.7 \\
\cline { 2 - 4 } & Absent & 20 & 33.3 \\
\hline ZN Staining for AFB & Present & 8 & 13.3 \\
\cline { 2 - 4 } & Absent & 52 & 86.7 \\
\hline & Positive & 24 & 40.0 \\
\cline { 2 - 4 } & Negative & 36 & 60.0 \\
\hline
\end{tabular}

ZN stain - Ziehl-neelson stain

Table-3: Cellular and Tissue Diagnosis

\begin{tabular}{|l|l|l|l|}
\hline \multicolumn{2}{|c|}{} & No. of Cases & Percentage \\
\hline \multirow{2}{*}{ Method of diagnosis } & FNAC & 54 & 90 \\
\cline { 2 - 4 } & Biopsy & 6 & 10 \\
\hline \multirow{2}{*}{ Caseous Necrosis } & Present & 44 & 73.3 \\
\cline { 2 - 4 } & Absent & 16 & 26.6 \\
\hline \multirow{2}{*}{ Epithelioid Cell } & Present & 54 & 90 \\
\cline { 2 - 4 } & Absent & 6 & 10 \\
\hline \multirow{2}{*}{ Giant Cell } & Present & 16 & 26.6 \\
\cline { 2 - 4 } & Absent & 44 & 73.3 \\
\hline
\end{tabular}

FNAC- Fine-needle aspiration cytology

Table-4: Screening Test Results

\begin{tabular}{|l|l|l|}
\hline & No. of Cases & Percentage \\
\hline LNTB & 52 & 86.6 \\
\hline Hodgkins Lymphoma & 4 & 6.6 \\
\hline Metastatic Lymphadenopathy & 2 & 3.3 \\
\hline Reactive Lymphaadenitis & 2 & 3.3 \\
\hline
\end{tabular}

LNTB- Lymph node tuberculosis

\section{Conclusion}

Early and accurate diagnosis of extrapulmonary TB has been an area of active research in literature. TB of the cervical lymph nodes is a common disease. However, at times presenting signs and symptoms of cervical lymph node TB can be varied and often misleading. It is important for the clinician to be aware of the condition and consider it in their differential diagnosis. Accurate and specific diagnostic tests that can detect the disease early is the need of the 
hour. High index of suspicion for possibility of TB should be kept in mind while investigating such cases in a country like India, where the prevalence of $\mathrm{TB}$ is high.

\section{Conflict of Interest: None.}

\section{REFERENCES}

1. King D, Ramachandra J, Yeomanson D. Lymphadenopathy in children: refer or reassure?"Archives of disease in childhood. Education and practice.2014;99(3):101-10.

2. Ferrer R. Lymphadenopathy: differential diagnosis and evaluation. Am Fam Physician. 1998;58:1313-20.

3. Steel BL, Schwartz MR, Ramzy I. Fine needle aspiration biopsy in the diagnosis of lymphadenopathy in 1,103 patients. Role, limitations and analysis of diagnostic pitfalls. Acta cytologica. 1995;39(1):76-81.

4. Lioe TF, Elliott H, Allen DC, Spence RA. The role of fine needle aspiration cytology (FNAC) in the investigation of superficial lymphadenopathy; uses and limitations of the technique. Cytopathology. 1999 Oct;10(5):291-7.

5. Kent DC. Tuberculous lymphadenitis: not a localized disease process. Am J Med Sci 1967;254(6):866-74.

6. Golden MP, Vikram HR. Extrapulmonary tuberculosis: an overview. Am Fam Physician. 2005;72(9):1761-8.

7. Tatar D, Senol G, Alptekin S, Gunes E. Assessment of lymph node tuberculosis in two provinces in Turkey. Japanese journal of infectious diseases. 2011;64(4):316-21.
8. Jha BC, Dass A, Nagarkar NM, Gupta R, Singhal S. Cervical tuberculous lymphadenopathy: changing clinical pattern and concepts in management. Postgraduate medical journal. 2001;77(905):185-7.

9. Geldmacher H, Taube C, Kroeger C, Magnussen $\mathrm{H}$, Kirsten DK. Assessment of lymph node tuberculosis in northern Germany: a clinical review. Chest. 2002;121(4):1177-82.

10. Kanlikama M, Mumbuç S, Bayazit Y, Sirikçi A. Management strategy of mycobacterial cervical lymphadenitis. J Laryngol Otol. 2000;114(4):2748.

11. Penfold CN. A review of 23 patients with tuberculosis of the head and neck. British Journal of oral and maxillofacial surgery. 1996;34(6):50810.

12. Artenstein AW, Kim JH, Williams WJ, Chung RC. Isolated peripheral tuberculous lymphadenitis in adults: current clinical and diagnostic issues. Clin Infect Dis. 1995;20(4):876-82.

13. Polesky A, Grove W, Bhatia G. Peripheral tuberculous lymphadenitis: epidemiology, diagnosis, treatment, and outcome. Medicine. 2005;84(6):350-62.

14. Konishi K, Yamane H, Iguchi H, Nakagawa T, Shibata S, Takayama M. Study of tuberculosis in the field of otorhinolaryngology in the past 10 years. Acta Otolaryngol. 1998; 118(538):244-9.

15. Olson NR. Atypical mycobacterial infections of the neck. The Laryngoscope. 1967 Aug;77(8):1376-89.

16. Khandkar C, Harrington Z, Jelfs PJ, Sintchenko V, Dobler CC. Epidemiology of peripheral lymph node tuberculosis and genotyping of $\mathrm{M}$. tuberculosis strains: A case-control study. PloS one. 2015;10(7):e0132400. 